\title{
30 ANOS DO RELATÓRIO BRUNDTLAND: NOSSO FUTURO COMUM E O DESENVOLVIMENTO SUSTENTÁVEL COMO DIRETRIZ CONSTITUCIONAL BRASILEIRA
}

\section{YEARS OF THE BRUNDTLAND REPORT: OUR COMMON FUTURE AND SUSTAINABLE DEVELOPMENT AS A BRAZILIAN CONSTITUTIONAL DIRECTIVE}

\author{
Carlos Eduardo Japiassú ${ }^{1}$ \\ Isabella Franco Guerra ${ }^{2}$
}

\section{Resumo}

O presente artigo tem como motivação a discussão sobre as premissas do desenvolvimento sustentável tendo como base os princípios de dignidade humana, a Declaração do Rio de 1992 e a Constituição de 1988. A análise estrutura-se, inicialmente, discutindo o direito fundamental ao meio ambiente equilibrado, com posterior apresentação do Relatório Brundtland e a Declaração do Rio de 1992. Em seguida, analisa-se a obrigatoriedade do Estado como atuante na defesa do meio ambiente. Por fim, debate-se a responsabilidade e a proibição de retrocesso ambiental à luz da Constituição Brasileira de 1988.

Palavras-chave: Dignidade Humana; Direitos Humanos; Meio Ambiente; Relatório Brundtland; Desenvolvimento Sustentável; Intervenção Estatal; Constituição Brasileira; Proibição de Retrocesso.

\begin{abstract}
This article has the motivation to discuss the premises of sustainable development based on the principles of human dignity, the Rio Declaration of 1992 and the Constitution of 1988. The analysis is structured initially, discussing the fundamental right to the environment with a subsequent presentation of the Brundtland Report and the Rio Declaration of 1992. Next, the State's obligation to defend the environment is analyzed. Finally, we debate the responsibility and the prohibition of environmental regression in light of the Brazilian Constitution of 1988.
\end{abstract}

Keywords: Human Dignity; Human Rights; Environment; Brundtland Report; Sustainable Development; State Intervention; Brazilian Constitution; Prohibition of Retreat.

\footnotetext{
${ }^{1}$ Professor Associado de Direito Penal da Universidade do Estado do Rio de Janeiro e da Universidade Federal do Rio de Janeiro. Coordenador do Programa de Pós-Graduação em Direito da Universidade Estácio de Sá -Mestrado e Doutorado. E-mail: japiassu@uerj.br

${ }^{2}$ Mestre em Direito pela PUC-Rio. Professora da PUC-Rio. E-mail: ifguerra@puc-rio.br
} 


\section{INTRODUÇÃO}

A defesa do meio ambiente é matéria de interesse público, pois diz respeito à preservação da vida e das condições de sua existência, além de tratar da proteção de um bem de uso comum a todos os habitantes do planeta. Isto, por si só, demonstra que o interesse na matéria é global e também é local, demandando o compromisso de todos em busca da manutenção da segurança e da higidez do ambiente.

Nesse sentido, importantes esforços foram realizados pelas Nações Unidas para conseguir formalizar os compromissos por parte dos países integrantes da comunidade internacional, em prol da proteção do meio ambiente, merecendo destaque as Conferências de Cúpula organizadas na esfera do Programa das Nações Unidas para o Meio Ambiente, envolvendo o debate sobre desenvolvimento e meio ambiente.

Alguns avanços ocorreram, sem sombra de dúvida, nos últimos 40 anos, porém ainda há um longo percurso para alcançar a efetividade da preservação dos recursos naturais, do equilíbrio dos ecossistemas e da chamada sustentabilidade ambiental. Atualmente, no Brasil, a preocupação com os riscos de retrocessos legislativos é grande. Portanto, são necessárias tanto a manutenção das conquistas introduzidas na legislação brasileira, muitas delas impulsionadas pelos compromissos assumidos pelo Estado brasileiro perante a Organização das Nações Unidas, como também a sua adequada implementação.

Nesse cenário, no presente artigo, pretende-se, a partir dos textos normativos, da doutrina especializada e de decisões de Tribunais Superiores brasileiros, discutir as premissas do desenvolvimento sustentável tendo como matriz a dignidade humana, os princípios da Declaração do Rio de 1992 e da Constituição de 1988.

Para tanto, inicialmente, tratar-se-á do direito fundamental ao meio ambiente ecologicamente equilibrado. A seguir, apresentar-se-á o Relatório Brundtland e a Declaração do Rio de 1992. O ponto seguinte será analisar o desenvolvimento sustentável e a intervenção obrigatória do Estado na defesa do meio ambiente. Ao final, discutir-se-á a sustentabilidade, a responsabilidade e a proibição de retrocesso ambiental à luz da Constituição Brasileira de 1988.

\section{O DIREITO FUNDAMENTAL AO MEIO AMBIENTE ECOLOGICAMENTE EQUILIBRADO}

O meio ambiente ecologicamente equilibrado está incluído entre os chamados direitos difusos, que têm como características a indivisibilidade, seus titulares são indeterminados e não 
estão unidos por nenhuma relação jurídica base. Os titulares têm tão-somente, entre si, um interesse fático comum. Trata-se, como explica Celso Antonio Pacheco Fiorillo, de um objeto que, ao mesmo tempo, a todos pertence, mas ninguém em específico o possui.

É importante compreender o aspecto extrapatrimonial do meio ambiente, haja vista que além do aspecto material tem expressão imaterial. Fiorillo ressalta também o sentido de ubiquidade do meio ambiente, pois ele diz respeito ao que está em toda parte, em todo lugar, o que explica a conceituação contida no inciso III, do artigo 3 da Lei no 6938 de 1981, que diz ser o conjunto de condições, influências, interações de ordem química, física e biológica que promovem e abrigam a vida em todas as suas formas. Consequentemente, proteger o meio ambiente é também proteger as condições que possibilitam que a vida ocorra. Paulo Affonso Leme Machado chama a atenção para o fato de que o meio ambiente deve ser considerado como um conjunto de fatores naturais em equilíbrio entre si.

Compreender o significado de meio ambiente envolve adotar uma visão holística, integrada e perceber as suas múltiplas e complexas relações, envolvendo aspectos ecológicos, psicológicos, legais, políticos, sociais, econômicos, científicos, culturais e éticos. O significado e o alcance da expressão meio ambiente importa, pelo exposto, na adoção de um olhar unitário, considerando-o em seus aspectos globais e locais, porém, sem descurar de que não se trata de pensar o meio ambiente como a simples soma de seus componentes (dos recursos ambientais como água, solo, ar), mas da compreensão como um todo, como um bem jurídico autônomo e essencial à vida.

Meio ambiente seguro é um direito fundamental, constitucionalmente assegurado, de titularidade transindividual, isto é, indivisível e pertencente a toda a coletividade. Trata-se de um bem que é indisponível e imprescritível e, por isso, incumbe a todos, cidadãos e Poder Público, unir esforços para a sua proteção.

Vale dizer que os direitos fundamentais configuram "o conjunto de direitos e liberdades institucionalmente reconhecidos e garantidos pelo direito positivo", portanto estão relacionados à dignidade humana.

Rosen, com base nos referenciais kantianos, relaciona a dignidade com a ideia de que os seres humanos são todos dotados de um valor intrínseco, incondicional, considerando que os seres humanos jamais podem ser tratados como meios, pois os seres humanos são fins em si mesmos. Dignidade, portanto, é algo intangível, inalienável e que constitui o fundamento das reivindicações morais que os sustentam, pela simples razão de serem humanos. 
O homem, como agente dotado de racionalidade, é, ao mesmo tempo, responsável por si mesmo e também tem responsabilidade em relação ao outro. A sustentabilidade ambiental reafirma essa responsabilidade do homem em relação à manutenção da higidez ambiental, das condições estéticas e sanitárias do meio ambiente, da preservação da biodiversidade, que é tanto uma responsabilidade para consigo mesmo, já que são condições para a sadia qualidade de vida, como configura uma responsabilidade para com aqueles que ainda virão, havendo a solene responsabilidade de legar às futuras gerações no mínimo o mesmo grau de acesso aos recursos ambientais que recebeu, tendo ainda um dever de buscar promover a melhoria das condições do meio ambiente. Daí os laços de solidariedade intergeracionais.

\section{O RELATÓRIO BRUNDTLAND, A DECLARAÇÃO DO RIO 92 E AS PREMISSAS DO DESENVOLVIMENTO SUSTENTÁVEL}

A Conferência de Cúpula realizada em Estocolmo, no ano de 1972, sobre Meio Ambiente e Desenvolvimento, foi um marco para o Direito Ambiental, pois os Chefes de Estado reunidos discutiram e aprovaram diretrizes comuns para enfrentar os problemas relacionados ao uso dos recursos naturais, concernentes aos impactos causados sobre o meio ambiente originados de processos industriais e relacionados à exploração predatória da natureza. Nesse contexto, novos horizontes sobre o tema do crescimento econômico e do desenvolvimento foram trazidos para o cenário global.

A partir do início dos anos 1970, foram realizadas diversas conferências internacionais e assinadas declarações e convenções quadro internacionais sobre meio ambiente, envolvendo grande variedade de temas, como clima, proteção da biodiversidade e desenvolvimento sustentável, com o intuito de desenvolver diretrizes comuns para as ações atinentes à proteção do meio ambiente, por meio de um esforço integrado da comunidade internacional.

A Declaração de Estocolmo sobre o Ambiente Humano, de 16 de junho de 1972, refletindo a preocupação com a preservação e melhoria do ambiente humano, enfatiza que:

o homem tem o direito fundamental à liberdade à igualdade e ao desfrute de condições de vida adequadas, em um meio ambiente de qualidade tal que the permita levar uma vida digna, gozar de bem-estar e é portador solene de obrigação de proteger e melhorar o meio ambiente, para as gerações presentes e futuras (...).

O desenvolvimento econômico e social é indispensável para assegurar ao homem um ambiente de vida e trabalho favorável (...).

É indispensável um trabalho de educação em questões ambientais, visando tanto às gerações jovens como os adultos, dispensando a devida atenção ao setor das populações menos privilegiadas, para assentar as 
bases de uma opinião pública bem informada e de uma conduta responsável dos indivíduos, das empresas e das comunidades (...).

Note-se, pelo texto da Declaração de Estocolmo, que, em 1972, a comunidade internacional já reconhecia o direito do homem de desfrutar de um meio ambiente de qualidade tal, que the permita uma vida digna, ao mesmo tempo que tem a obrigação de proteger e melhorar o meio ambiente para as gerações presentes e futuras.

A diretriz internacional exposta na Declaração enfatiza que a promoção da educação ambiental é indispensável, sendo também necessário informar a população sobre as questões ambientais, tendo, ainda, assentado a necessidade de que todos, cidadãos, empresas e comunidades tenham uma conduta responsável em relação ao meio ambiente.

É preciso mencionar que o Brasil, apesar de ter participado da reunião de Cúpula em Estocolmo e de ter assinado a Declaração sobre Meio Ambiente Humano, não a implementou de maneira adequada naquele momento.

A política brasileira, ao tempo dos governos militares, era marcadamente desenvolvimentista, caracterizada por grandes obras públicas de infraestrutura questionáveis e ambientalmente preocupantes, como a construção da Rodovia Transamazônica e a instalação da usina nuclear em Angra dos Reis. Também foi, nesse período, o auge da poluição na cidade paulista de Cubatão.

Pode-se dizer que a preocupação com o crescimento econômico deixou a questão ambiental de lado. A Declaração de Estocolmo, embora significasse um compromisso do Estado de adotar medidas para implementá-la, não possuía um mecanismo de execução forçada dos seus ditames, como é característico das chamadas soft law.

Foi somente a partir do advento da Lei no 6.803/1980, que houve um impulso de sistematização pelo Poder Público brasileiro em relação à proteção ambiental e exercício do poder de polícia administrativo na defesa do meio ambiente. A chamada Lei de Zoneamento Industrial, de maneira inovadora, incluiu a necessidade de avaliação ambiental antes do órgão público competente aprovar a localização e instalação de indústria.

É possível afirmar que a década de 1980 foi marcada por uma série de inovações legislativas em matéria ambiental, que significaram a adoção das diretrizes constantes na Declaração de Estocolmo pelo ordenamento jurídico brasileiro. Importante mencionar a Lei da Política Nacional do Meio Ambiente (Lei no 6.938/1981), que introduziu as bases do Sistema Nacional do Meio Ambiente- SISNAMA, estabeleceu instrumentos de proteção relacionados à prevenção, como por exemplo a exigência do estudo prévio de impacto ambiental e o 
licenciamento ambiental, além de ter previsto mecanismos de repressão e reparação do dano, adotando a responsabilidade civil objetiva ( artigo $14 \S 1$ 으) e impondo ao Ministério Público o dever de promover a ação civil de responsabilidade por dano ao meio ambiente. A Lei da Ação Civil Pública (Lei no 7347/1985) também deve ser lembrada, pois introduziu um importantíssimo mecanismo de tutela coletiva, que permitiu a entes intermediários da sociedade, tais como as associações e o Ministério Público, promover, em juízo, a defesa do direito difuso ao meio ambiente.

Em que pese a relevância das iniciativas anteriores, pode-se dizer que no Brasil o efetivo incremento da tutela do meio ambiente decorreu da Constituição de 1988.

A Constituição estabeleceu as atribuições dos entes políticos de proteger o meio ambiente; previu a matriz principiológica, que está delineada em diversos dispositivos, entre os quais, o artigo 170, que fixou, como princípio da Ordem Econômica, a defesa do meio ambiente, e, no título da Ordem Social, no capítulo próprio sobre o meio ambiente, firmou os ditames da prevenção e os laços do compromisso ético das presentes gerações de legar o acesso aos recursos ambientais às gerações futuras.

Quanto ao cenário internacional, em 1983, a Assembleia Geral das Nações Unidas aprovou a criação da Comissão Mundial sobre o Meio Ambiente e o Desenvolvimento Humano, tendo sido designada como presidente a então a Primeira Ministra da Noruega, Gro Harlem Brundtland.

O relatório elaborado pela Comissão, denominado "Nosso Futuro Comum", forneceu os lineamentos e os indicadores preparatórios para a Conferência de Cúpula de 1992, realizada no Rio de Janeiro, de forma que trazia as bases para a inserção do desenvolvimento sustentável na construção dos textos dos diversos documentos firmados e compromissos assumidos pelos Estados que participaram da reunião de Cúpula e para aqueles que assinaram os acordos nos tratados aprovados.

Em 1992, de 3 a 14 de junho, na Conferência de Cúpula na Cidade do Rio de Janeiro, os Estados participantes reafirmaram a Declaração da Conferência das Nações Unidas sobre o Meio Ambiente Humano, adotada em Estocolmo em 1972, com o espírito de parceria global e perspectivas de novos níveis de cooperação internacional entre os Estados, os setores chaves da sociedade e indivíduos, com vistas a respeitar e a proteger a integridade do sistema global de meio ambiente, adotando valores comuns, proclamando que os seres humanos têm direito a uma vida saudável e produtiva em harmonia com a natureza, afirmando que os seres humanos estão no centro das preocupações com o desenvolvimento sustentável. 
A Declaração do Rio de Janeiro sobre Meio Ambiente e Desenvolvimento, de 1992, apresenta um rol de princípios que instituem orientações fundamentais, tais como: a concepção de uso equitativo dos recursos naturais, já que as gerações presentes não podem privar as gerações futuras do acesso ao meio ambiente ecologicamente equilibrado; o estabelecimento da proteção ambiental integrada ao processo de desenvolvimento para que este seja sustentável; a fixação da cooperação dos Estados e dos indivíduos, como requisito indispensável para alcançar o desenvolvimento sustentável, a erradicação da pobreza e a redução das disparidades de padrões de vida da população mundial; a importância do dever de precaução e do princípio do poluidor pagador.

Paulo Affonso Leme Machado explica que o homem não é a única preocupação do desenvolvimento sustentável. Diz ele que nem sempre o homem deverá ocupar o centro da política ambiental, que a proteção da natureza deve integrar o desenvolvimentos sustentável, Haverá casos em que, para proteger o bem estar humano e para colocar em prática a harmonia com a natureza, será preciso conservar a vida dos animais e plantas em áreas declaradas inacessíveis ao próprio homem.

Percebe-se, portanto, que a proteção do meio ambiente e o uso equitativo dos recursos naturais são necessários para que possam ser atendidas as necessidades das gerações presentes sem comprometer os direitos das gerações futuras, por meio de uma lógica de solidariedade entre as gerações.

O Princípio 10 da Declaração do Rio estabelece que os Estados promoverão o acesso adequado dos cidadãos às informações ambientais e irão assegurar os níveis apropriados de participação dos interessados, facilitando e estimulando a conscientização e a participação popular, bem como garantindo o acesso a mecanismos judiciais e administrativos inclusive para a compensação e reparação de danos.

A grande preocupação constante nas Declarações Internacionais sobre Meio Ambiente diz respeito à prevenção de danos e à necessidade de conciliar a utilização de recursos naturais sem promover o esgotamento desses recursos ou causar a poluição, de forma que o equilíbrio ambiental seja mantido. Portanto, um dos grandes desafios diz respeito a atender às necessidades das gerações presentes, sem comprometer o acesso aos recursos ambientais das gerações futuras.

Mais que isso, a Declaração do Rio de 1992, em seu princípio 15, adota a precaução de forma que os Estados deverão pautar suas decisões considerando a necessidade de evitar danos ambientais, levando em conta os riscos e o problema da ameaça de danos sérios e 
irreversíveis ao meio ambiente, consequentemente, a lógica é a de buscar a mais ampla segurança possível agindo com prudência e cautela.

Desse contexto de precaução, considerando a redação do princípio 15 da Declaração do Rio, quatro características sobre a proteção do meio ambiente devem ser destacadas. A primeira é que a intensidade de proteção jurídica por parte de cada Estado está limitada à sua capacidade, por isso, não é uma proteção absoluta; a segunda é que a ameaça de danos sérios e irreversíveis, mesmo que hipotética, se for plausível, justifica a intervenção do Estado sem a necessidade de que o dano tenha se configurado concretamente ou se mostrado temporalmente provável; a terceira é a de não haver a exigência de certeza científica absoluta da determinação do dano plausível, sendo apenas necessário que dito dano, no conjunto dos conhecimentos científicos disponíveis na ocasião, possa legitimamente apresentar-se potencialmente sério e irreversível, finalmente, que as medidas econômicas para evitar o dano ambiental sejam compatíveis com outras de ordem social e de desenvolvimento econômico.

As Declarações Internacionais se apoiam sobre compromissos morais assumidos por Estados soberanos. Esses tratados moldam e fortalecem obrigações comuns, nesse sentido, os compromissos assumidos pelo Brasil relacionados à proteção do meio ambiente têm como consequência o dever de elaborar, no âmbito do direito interno, normas que respeitem as diretrizes firmadas nesses documentos internacionais, bem como aplicá-las na formulação das políticas públicas, na definição do planejamento econômico, respeitando e tomando como base para as decisões públicas os limites ambientais, a necessidade de informar suficientemente e de forma clara a coletividade, fixando o dever do Estado de adotar medidas e prever mecanismos para implementar a sustentabilidade ambiental.

Em 2002, houve a Conferência de Johanesburgo sobre Meio Ambiente e Desenvolvimento, também promovida pelas Nações Unidas como um encontro de Cúpula Mundial, mas não ocorreram grandes avanços em termos de redução do uso de combustíveis fósseis, padrões mundiais de consumo e estratégias para uma maior proteção do meio ambiente.

Adiante, em 2012, ocorreu, no Rio de Janeiro, a reunião de Cúpula promovida denominada Rio +20 , em que a preocupação principal era com os riscos de retrocessos em relação às conquistas obtidas no encontro de 1992, principalmente no tocante às questões climáticas e proteção da diversidade biológica. Michel Prieur ressalta ter sido a ocasião que oficialmente foi suscitada a discussão acerca da importância da não regressão como condição para o desenvolvimento sustentável. 


\section{O DESEnVOLVIMENTO SUSTENTÁVEL E A INTERVEnÇÃO OBRIGATÓRIA DO ESTADO NA DEFESA DO MEIO AMBIENTE}

Com base nos princípios estabelecidos nos tratados internacionais sobre meio ambiente e nas diretrizes da Ordem Econômica e da Ordem Social da Constituição brasileira de 1988, notadamente o disposto nos artigos 170, inciso VI, 174, 182, 186 e 225, verifica-se que o papel do Estado na defesa do meio ambiente e na busca da realização da justiça ambiental é crucial. Nessa esteira, o planejamento público tem que levar em consideração a realidade econômica, as demandas sociais e os limites ambientais.

Tendo em vista a matriz constitucional, pode-se dizer que as premissas que embasam o Direito Ambiental brasileiro têm em sua base a prevenção, a precaução, a sustentabilidade, o controle pelo Poder Público de atividades que possam repercutir negativamente sobre o meio ambiente, a transparência, a participação popular e responsabilização do poluidor.

Do disposto no caput do artigo 225 combinado com o firmado no artigo 170, inciso VI da Constituição de 1988 infere-se que o desenvolvimento só é alcançado quando os direitos de liberdade são respeitados, os direitos sociais assegurados, o crescimento econômico esteja conjugado à melhoria da qualidade de vida da população. Desenvolvimento também significa acesso aos direitos econômicos, sociais, culturais e ambientais, de modo que a exploração dos recursos naturais ocorra em conformidade com as condições de segurança ambiental, mantendo a perenidade desses recursos e que, assim, as presentes e futuras gerações tenham acesso ao meio ambiente ecologicamente equilibrado, que é bem de uso comum do povo essencial à sadia qualidade de vida, como diz o texto constitucional.

As questões atinentes ao meio ambiente são de ordem pública, uma vez que envolvem um bem de uso comum do povo, por isso cabe ao legislador aprovar leis para a sua proteção, sendo necessária também a intervenção estatal no controle de atividades que geram riscos ambientais, por meio do exercício do poder de polícia administrativo.

A fim de garantir o controle sobre atividades que possam repercutir negativamente sobre o meio ambiente, a Constituição brasileira prevê a competência comum dos entes federativos para a proteção do meio ambiente. Está expresso no artigo 23, inciso VI da Constituição, o dever do Poder Executivo de adotar ações na promoção da defesa do meio ambiente. Dessa forma, o Poder Público não pode abrir mão do exercício do poder de polícia administrativo na seara ambiental. 
O controle sobre as atividades que envolvem riscos sobre a segurança ambiental é, portanto, uma exigência para atender aos comandos do princípio da prevenção, imprescindível para o bem-estar das presentes e futuras gerações, como também para a proteção das várias espécies e ecossistemas.

Partindo da premissa de que não há liberdade sem acesso aos direitos fundamentais, o desenvolvimento sustentável só será possível se os recursos ambientais forem utilizados de forma racional e estiver garantido o acesso da população à água potável, aos direitos sociais, à moradia digna, à energia e ao saneamento básico, em um meio ambiente hígido, com a proteção da saúde, com acesso à educação e pleno emprego, garantindo o direito à participação no processo político de tomada de decisões, pois estas questões envolvem a proteção da dignidade da pessoa humana.

Desenvolvimento sustentável é a expressão que se traduz na promoção simultânea e equilibrada da proteção ambiental, da inclusão social e do crescimento econômico.

É preciso desenvolvimento para haver liberdade, mas para haver desenvolvimento é preciso assegurar dignidade às pessoas, condições de bem-estar, acesso à saúde, saneamento básico, moradia, educação, trabalho, cultura, em um meio ambiente equilibrado.

Pode-se dizer, portanto, que o Estado tem o dever de atuar na defesa do meio ambiente, tendo em vista que as catástrofes ambientais, os desastres provocados pelas intervenções humanas negativas sobre o meio ambiente, geram graves problemas sociais e econômicos, consequentemente tornam obrigatória a adoção de medidas de prevenção e que favoreçam o planejamento econômico ambientalmente responsável e eficiente.

\section{A SUSTENTABILIDADE, A RESPONSABILIDADE E A PROIBIÇÃO DE RETROCESSO AMBIENTAL À LUZ DA CONSTITUIÇÃO BRASILEIRA DE 1988}

O disposto no caput do artigo 225 da Constituição brasileira possibilita traçar a relação entre democracia, defesa do meio ambiente, solidariedade entre as gerações, desenvolvimento sustentável, participação popular e controle pelo poder público de atividades que geram riscos de danos sérios e irreversíveis para o meio ambiente. A interpretação do texto normativo do dispositivo constitucional ora referido leva a essa conexão. O constituinte brasileiro ressaltou que o meio ambiente ecologicamente equilibrado é essencial para a sadia qualidade de vida, qualificando-o como bem de uso comum do povo e, portanto, é lógico concluir que se trata de um direito fundamental. Por ser essencial à sadia qualidade de vida, tem que ser protegido para 
as presentes e futuras gerações, configurando, assim, os laços intergeracionais e o compromisso ético que a todos se impõe de protegê-lo, demandando tanto as ações do Poder Público quanto da coletividade no sentido da defesa do equilíbrio ambiental.

Por ser matéria de interesse comum da humanidade e por estar atrelada ao bem-estar de todos, o comportamento esperado é o de agir de forma refletida e com vistas a evitar os danos ambientais. Nesse sentido, atender aos comandos dos princípios da prevenção e da precaução é primordial. Logo, como determina a prevenção, é preciso adotar todos os meios e mecanismos existentes para conter os riscos de danos ao meio ambiente nas situações previsíveis e conhecidas. Na esfera de precaução, a falta de certeza científica não é uma autorização para agir de forma imprudente, ao contrário, nas situações ainda desconhecidas pela ciência, havendo a potencialidade ou a probabilidade, ainda que remota, de dano sério ou irreversível ao meio ambiente, a conduta deverá ser a da cautela. Há o dever da coletividade de promover a proteção do meio ambiente e agir com prudência.

O dever de defesa do meio ambiente tem como uma de suas consequências a incumbência de ação por parte dos cidadãos, estes têm responsabilidades quanto ao rumo da Nação, por isso têm que deixar de lado posturas passivas e começar a trilhar os caminhos para ativamente poder tomar parte das decisões suscetíveis de repercutir sobre o meio ambiente.

As condutas proativas são esperadas por parte de todos para que haja a salvaguarda do meio ambiente.

Nesse condão, aquele que provocar direta ou indiretamente a poluição ambiental responderá por ela, é o que diz a Constituição de 1988 no artigo 225, §3o e a legislação infraconstitucional.

O dano ao meio ambiente pode ensejar a responsabilidade civil, a administrativa e a penal. Essas esferas são independentes. A Lei no 6.938 de 1981 fixou no artigo 14 §1으 a responsabilidade civil objetiva pelo dano ao meio ambiente. A Lei no 9.605 de 1998 tratou da responsabilização penal e administrativa. Na esfera penal, o ordenamento jurídico brasileiro avançou ao admitir a possibilidade da responsabilidade penal da pessoa jurídica.

A Constituição de 1988 rompeu com o dogma da societas delinquere non potest, prevendo, nos arts. $173, \S 50$ e $225, \S 3$, a possibilidade de sanções penais para as pessoas jurídicas. Nesse passo, a Lei no 9.605/98 legislou sobre o assunto, prevendo, no seu art. 3ํ, que as pessoas jurídicas serão responsabilizadas administrativa, civil e penalmente, nos casos em que a infração seja cometida por decisão de seu representante legal ou contratual, ou de seu órgão colegiado, no interesse ou benefício da entidade. O parágrafo único, do citado art. 3으, 
dispôs que a responsabilidade das pessoas jurídicas não exclui a das pessoas físicas, autoras, coautoras ou partícipes do mesmo fato.

Cuida-se do modelo de imputação subsequente ou de empréstimo - também chamado de imputação por ricochete -, por intermédio do qual para que seja atribuída responsabilidade ao ente moral faz-se necessária a atuação de uma pessoa física a ela vinculada e em seu benefício ou interesse. Em outros termos, a infração ambiental deve ser praticada no interesse da pessoa jurídica e não em proveito pessoal. Ademais, a atividade lesiva ao Meio Ambiente deve ser executada por alguém que se encontre estreitamente ligado à pessoa coletiva, "sempre com o auxílio do seu poderio, o qual é resultante da reunião das forças econômicas agrupadas em torno da empresa."

A responsabilização penal da pessoa jurídica pela prática de delitos ambientais advém de uma escolha política, como forma não apenas de punição das condutas lesivas ao meioambiente, mas como forma mesmo de prevenção. A simples adoção da responsabilidade penal da pessoa jurídica pela Constituição Federal demonstra a importância conferida pelo constituinte à proteção do meio ambiente.

No âmbito penal é também interessante verificar a aplicação do princípio da precaução como base para decisões judiciais. Em casos de delitos contra o meio ambiente, os tribunais brasileiros não têm admitido a sua insignificância em virtude da adoção do princípio da precaução.

Existem outras referências ao princípio da precaução, geralmente, nos casos de delitos contra o meio ambiente previstos na Lei no 9.605/1998 ou de outros delitos, mas que podem ter um impacto sobre o meio ambiente. Isto se deve ao fato de que os tribunais brasileiros reconhecem a adoção do princípio da precaução como elemento fundamental em matéria de Direito do Ambiental e de Direito Penal Ambiental.

Em todos esses casos, a justificação da adoção do princípio da precaução, em detrimento de outros princípios, decorre do fato de que crimes contra o meio ambiente constituem delitos de perigo abstrato.

Assim, o perigo abstrato ocorre em casos em que o legislador, discricionariamente, define uma conduta como ontologicamente perigosa, isto é, sem a possibilidade de provas empíricas da ameaça de lesão ao bem jurídico penalmente tutelado. Não se trata de ausência de prova de perigo, mas de impossibilidade efetiva de prova. Percebe-se, assim, que o risco é determinante para a aplicação do instituto. No entanto, o seu efeito pode ser muito diferente daquele perseguido pelo princípio da precaução. 
Na esfera cível, é relevante ressaltar que a responsabilidade é objetiva. Os princípios, tanto o da reparação integral do dano quanto o do poluidor pagador, reforçam a adoção da responsabilidade civil sob a modalidade do risco integral, razão pela qual, não são aceitos o caso fortuito e a força maior como excludente de ilicitude.

Os Tribunais Superiores brasileiros têm enfrentado e julgado muitas demandas envolvendo matéria ambiental, avançando na determinação da reparação integral do dano, amparada na necessidade de sustentabilidade, dever de observar a precaução e de recomposição do dano quando não se alcança a prevenção.

A título de exemplo é relevante citar algumas decisões do Superior Tribunal de Justiça na esfera cível que determinaram a recomposição de áreas protegidas e reparação integral do dano. No Recurso Especial no 1.362.456 - MS, relatado pelo Ministro Mauro Campbell Marques, foi enfrentada a questão da supressão irregular de vegetação de preservação permanente, nulidade de licença ambiental e responsabilidade civil objetiva do degradador, ocasião em que os Ministros do STJ entenderam que, quanto ao meio ambiente, a obrigação assumida pelo Estado brasileiro em diversos compromissos internacionais foi o de garantir o uso sustentável dos recursos naturais em favor das presentes e futuras gerações. Consideraram, também, que as restrições impostas às áreas de preservação permanente seguem o regime jurídico das limitações administrativas. Infere-se dessa decisão que há o dever do Poder Público de atuar de forma proba e de coibir a degradação ambiental.

Outra decisão da Segunda Turma do STJ, tratando de responsabilidade civil ambiental e recomposição de área de vegetação de preservação permanente, que merece registro é a do REsp no 176.753/SC, relatado pelo Ministro Herman Benjamin, explicando a essencialidade dessas áreas e funções ecológicas da mata ciliar.

Se é certo que, a partir de 1980, houve uma paulatina ampliação da proteção ambiental por meio da legislação e da jurisprudência, a Lei no 12.651/2012, que revogou o chamado Código Florestal (Lei no 4.771/1965) e dispôs sobre a proteção de vegetação nativa, introduziu o que, para muitos, constitui grave retrocesso, visto que reduziu as exigências de preservação ambiental.

A Lei no 12.651/2012 acolhe, nos artigos 1ำ, parágrafo único, e no caput do artigo 2ํㅡ, os princípios da preservação do meio ambiente, cooperação, ação governamental/intervenção estatal obrigatória na defesa do meio ambiente, desenvolvimento sustentável, função socioambiental da propriedade, que irão guiar a aplicação da legislação florestal. 
Contudo, ao revogar a Lei ำ 4.771/1965, introduziu mudanças significativas quanto ao tratamento das áreas de vegetação de preservação permanente, merecendo críticas inclusive no que diz respeito à sua recuperação nas pequenas propriedades rurais, isto é, aquelas que têm até quatro módulos fiscais.

A área de vegetação de preservação permanente (APP) está juridicamente definida no artigo 3ำ, inciso II, e seu regime legal está explicitado no artigo 7ㅇ. A APP configura uma limitação administrativa que recai sobre propriedades urbanas e rurais, públicas e privadas. É um tipo de espaço territorial especialmente protegido que, nos termos da lei e como o nome indica, será mantida imune ao corte raso, já que não pode, em regra, ser suprimida tendo em vista suas importantes funções ecológicas. Dentre elas, podem ser destacadas as de: assegurar o fluxogênico de fauna e flora, proteger a diversidade biológica, auxiliar na manutenção de estabilidade geológica, contribuir para evitar assoreamento de cursos d'água, sendo também importante para assegurar o bem estar humano.

Ocorre que, o legislador diminuiu a proteção no que diz respeito à vegetação riparia, aquela localizada nas margens dos cursos d’água, uma vez que passou a fixar como base para o cálculo da área o leito regular do rio e não mais o leito do rio em seu nível mais alto (artigo 4으, I); também modificou a exigência em relação ao topo de morro (artigo 4으, IX), passou a permitir o cômputo das áreas de vegetação de preservação permanente no cálculo da área da reserva legal das propriedades rurais (artigo 15).

A supressão ilegal provoca a responsabilização do proprietário, pois este tem o dever de respeitar o princípio da função socioambiental da propriedade, consequentemente, se ele vier a desmatar a área, será compelido a promover a devida recuperação do equilíbrio ambiental, reflorestando-a.

Um dos problemas, introduzidos pelo artigo 61-A da lei no 12.651 de 2102, é o tratamento dado às chamadas áreas consolidadas e a recuperação apenas parcial da vegetação de preservação permanente na pequena propriedade rural desmatada ilegalmente.

Há um tratamento desigual entre o proprietário que cumpriu o que já determinava a Lei no 4.771/1965 em relação à APP e o que descumpriu o dever de manter a vegetação ripária em áreas até quatro módulos fiscais.

Nesse caso, o proprietário que desmatou ilegalmente a área, em período anterior a 22 de julho de 2008, terá que recuperar apenas parcialmente a área de preservação permanente. Já o proprietário que tenha a propriedade localizada no mesmo Município, na mesma bacia hidrográfica, no mesmo bioma e com a mesma extensão de terras, e tenha cumprido 
exatamente o determinava a Lei no 4.771/1965, não terá o mesmo benefício quanto ao uso da área, visto que foi obrigado à preservação integral. Desse modo, é possível afirmar que a nova lei premiou o degradador.

A proteção dos interesses de pequenos proprietários rurais, como a viabilidade econômica de suas terras, não será resolvida com a diminuição de áreas de vegetação de preservação permanente. Outros caminhos deveriam ser adotados, como o acesso à tecnologia e ao conhecimento para explorar de forma sustentável a área, e a disponibilização de créditos e de financiamentos agrícolas diferenciados.

Diminuir espaços protegidos é desatender às bases do Direito Ambiental, pois não considera a necessária precaução. Essas áreas têm relevantes funções ecológicas e a sua supressão poderá repercutir negativamente quanto à manutenção do equilíbrio da bacia hidrográfica, dos ciclos hidrológicos, do fluxogênico, da diversidade biológica, podendo gerar impactos que podem se projetar para o futuro, tais como a diminuição de espécies e a redução do acesso à agua.

A Constituição brasileira, ao adotar, no caput do artigo 225, a ideia de equidade intergeracional, expressou o dever de proteção do meio ambiente para as gerações presentes e futuras, colocou em pauta a preocupação com a redução de parte da riqueza e da diversidade globais e firmou o dever ético de legar ao menos o mesmo grau de acesso aos recursos naturais, recebido das gerações predecessoras, para as futuras gerações.

Cabe refletir acerca do processo legislativo, sobre a técnica ou falta de técnica legislativa, sobre os fatores que influenciaram a aprovação desse texto normativo e a ausência de razoabilidade do tratamento dispensado à recomposição florestal em área de vegetação de preservação permanente na pequena propriedade ou posse rural, face à distância do disposto no artigo 225 da Constituição e ao retrocesso em comparação com o tratamento dado à matéria pela legislação revogada. Por conseguinte, também é necessário refletir sobre a imposição do dever constitucional de proteção, pelo Poder Público, do meio ambiente.

Nesse contexto, é forçoso concluir que o dever de proteger o meio ambiente também obriga o legislador a respeitar as bases constitucionais na elaboração e aprovação das leis, para que não haja retrocessos, principalmente quanto aos direitos fundamentais.

Nesse sentido, Ingo Sarlet sustenta que a proibição de retrocesso deve funcionar como uma barreira contra as tentativas de desmonte da legislação que promove os direitos fundamentais, pois a premissa é a de manter as conquistas legislativas, de seguir adiante e não 
retroceder, proteger as normas que cuidam de direitos fundamentais contra as tentativas de esvaziá-las.

Em relação à matéria ambiental, incluída, como já ressaltado nesse texto, na chamada terceira dimensão dos direitos humanos, a proibição de retrocesso é um comando a ser observado pelo legislador, que deve buscar a máxima efetividade da Constituição. Dessa forma, a lei nova não pode ser menos protetiva que a lei anterior. A proibição de retrocesso tem por objetivo funcionar como uma barreira e impedir a redução da proteção ambiental.

O princípio da proibição de retrocesso tem por escopo, portanto, assegurar o patamar de conquistas dos direitos fundamentais que asseguram a dignidade humana.

\section{CONCLUSÃO}

Os Estados, ao assinar tratados e convenções, assumem compromissos perante a comunidade internacional e, por isso, têm o dever de incorporar as diretrizes desses documentos internacionais à legislação interna e implementar políticas públicas que as concretizem.

Por influência de uma série de documentos internacionais, o direito brasileiro estabeleceu, em diversos dispositivos da Constituição de 1988 e na legislação infraconstitucional, a proteção do meio ambiente e lançou as bases para o desenvolvimento sustentável, que deve ser contínuo, durável e não comprometer o direito das gerações futuras a um meio ambiente ecologicamente equilibrado e à sadia qualidade de vida.

Assim, a proteção do meio ambiente constitui obrigação para o Poder Público e também vinculam o legislador, sob pena de promover verdadeiro retrocesso e de desrespeitar preceitos constitucionais. A inovação legislativa deve, portanto, ser sempre mais protetiva que a lei anterior, como medida necessária para a defesa e preservação do meio ambiente, bem de uso comum do povo e essencial à sadia qualidade de vida.

O grande desafio da sociedade brasileira consiste em conseguir que as decisões políticas não levem a retrocessos e que a sustentabilidade não seja posta de lado, para que não sejam causados danos no presente nem para as gerações futuras.

\section{REFERÊNCIAS BIBLIOGRÁFICAS}

BITENCOURT, Cezar Roberto. Tratado de Direito Penal. Parte Geral. São Paulo: Saraiva, 10. Ed., 2006, p. 182. 
BOBBIO, Norberto. A democracia e o poder invisível. In.: O Futuro da Democracia: uma Defesa das Regras do Jogo, 3ąed.tradução Marco Aurélio Nogueira. Rio de Janeiro: Paz e Terra, 1987, pp. 83-106.

CANOTILHO, José Joaquim Gomes, LEITE, José Rubens Morato (organizadores). Direito Constitucional Brasileiro. São Paulo: Saraiva, 2007.

FENSTERSEIFER, Tiago. Direitos Fundamentais e Proteção do Ambiente: a dimensão ecológica da dignidade humana no marco jurídico-constitucional do Estado Socioambiental de Direito. Porto Alegre: Livraria do Advogado Editora, 2008.

FIGUEIREDO, Guilherme José Purvin de. Curso de direito ambiental. 6a ed., rev., ampl. e atual. São Paulo: Revista dos Tribunais, 2013.

FIORILLO, Celso Antonio Pacheco. Curso de direito ambiental. 10a ed. rev., atual. e ampl. São Paulo: Saraiva, 2009.

GANEM, Roseli, ARAÚJO, Sueli Mara Vaz Guimarães de. Revisão do Código Florestal. Análise dos Projetos de Lei em Tramitação no Congresso Nacional. In.: Código Florestal Desafios e Perspectivas. Coord. SILVA, Solange Teles da, CUREAU, Sandra, LEUZINGER, Márcia Dieguez. São Paulo: Fiúza, 2010, p.376-401

GUERRA, Isabella Franco. Cadastro Ambiental Rural (CAR) e Programa de Regularização Ambiental (PRA) de Propriedades Rurais. In.: Comentários à Legislação Ambiental do Estado do Rio de Janeiro. Organizadora Cristiane Jaccoud. Rio de Janeiro: Lumen Juris, 2017, pp. 137-164.

Ação Civil Pública e Meio Ambiente. Rio de Janeiro: Forense, 1997.

Código Florestal Brasileiro. In.: Curso de Direito Ambiental. Coordenadores Flávio Ahmed e Ronaldo Coutinho. Rio de Janeiro: Lumen Juris, 2012, pp.337-361.

JAPIASSÚ, Carlos Eduardo Adriano. El principio de precaución en el derecho penal brasileño. MORAGA, Pilar; BOUTONNET, Mathilde; SAINT-PAU, Jean-Christophe. El principio precautorio en el derecho comparado. Santiago de Chile: CDA, 2015, p. 171-180.

JAPIASSÚ, Carlos Eduardo Adriano; SOUZA, Artur de Brito Gueiros. Curso de Direito Penal: Parte Geral - Arts. 10 a 120. 2a ed. rev. atual. e ampl. Rio de Janeiro: Forense, 2015.

MACHADO, Paulo Affonso. Direito Ambiental Brasileiro. 22 a ed, rev, ampl e atual. São Paulo: Revista dos Tribunais, 2014.

Direito à informação e meio ambiente. São Paulo: Malheiros, 2006.

MASCARENHAS, Luciane Martins de Araújo. Desenvolvimento Sustentável: Estudo de Impacto Ambiental e Estudo de Impacto de Vizinhança. Curitiba: Letra da lei, 2008

MILARÉ, Édis. Direito do ambiente, 10ed.São Paulo: Revista dos Tribunais, 2015.

PRIEUR, Michael. O Princípio da Proibição de Retrocesso Ambiental. In.: Colóquio Internacional Princípio da Proibição de Retrocesso Ambiental. Coordenador Antonio Herman Benjamin. Senado Federal. Comissão de Meio Ambiente, Defesa do Consumidor e Fiscalização e Controle, 2012, pp.11-54. 
ROSEN, Michael. Dignidade. São Leopoldo: Unisinos, 2015.

SARLET, Ingo Wolfgang. A eficácia dos Direitos Fundamentais. 11aed. Porto Alegre: Livraria do Advogado Editora, 2014.

SARLET, Ingo Wolfgang e FENSTERSEIFER, Tiago. Direito constitucional ambiental. São Paulo: Revista dos Tribunais, 2014.

SARLET, Ingo Wolfgang, MARINONI, Luiz Guilherme, MITIDIERO, Daniel. Curso de direito constitucional. 4a ed ampliada, incluindo novo capítulo sobre princípios fundamentais. São Paulo: Saraiva, 2015.

SARLET, Ingo Wolfgang; FENSTERSEIFER, Tiago. Estado socioambiental e mínimo existencial (ecológico?): algumas aproximações. SARLET, Ingo Wolfgang (org.). Estado socioambiental e direitos fundamentais. Porto Alegre: Livraria do Advogado Editora, 2010.

SEN, Amartya. Desenvolvimento Como Liberdade. Tradução de Laura Teixeira Motta. Revisão Técnica de Ricardo Doninelli Mendes. São Paulo: Companhia das Letras, 2000.

SENADO FEDERAL. Colóquio Internacional Princípio da Proibição de Retrocesso Ambiental. Coordenador Antonio Herman Benjamin. Senado Federal. Comissão de Meio Ambiente, Defesa do Consumidor e Fiscalização e Controle, 2012. http://www2.senado.leg.br/bdsf/item/id/242559

SHECAIRA, Sérgio Salomão. Responsabilidade penal da pessoa jurídica. 2a ed. S. Paulo: Método, 2003.

SILVA, Geraldo Eulálio do Nascimento e. Direito ambiental internacional. 2a edição rev e atualizada. Rio de Janeiro: Thex, 2002.

SILVA. José Afonso da. Direito ambiental constitucional. 3a ed. rev e atual. São Paulo: Malheiros, 2000.

SILVA SÁNCHEZ, Jesús-Maria. A expansão do Direito Penal. Aspectos da política criminal nas sociedades pós-industriais. São Paulo: Revista dos Tribunais, 2002, pp. 28-84.

SOARES, Guido Fernando Silva. Direito Internacional do Meio Ambiente: emergência, obrigações e responsabilidades. São Paulo: Atlas, 2001.

YOSHIDA, Consuelo Yatsuda Moromizato. A proteção do meio ambiente e dos direitos fundamentais correlatos no sistema constitucional brasileiro. In.: Temas fundamentais de direitos difusos e coletivos: desafios e perspectivas. Coord. YOSHIDA, Consuelo Yatsuda Moromizato, AHMED, Flávio, CAVALCA, Renata Falson. Rio de Janeiro: Lumen Juris, 2013, pp.166.

Trabalho enviado em 03 de setembro de 2017.

Aceito em 20 de outubro de 2017. 